https://doi.org/10.22319/rmcp.v12i4.5739

Artículo

\title{
Frecuencia de anticuerpos séricos contra los virus de la rinotraqueitis infecciosa bovina y diarrea viral bovina en toros, y su relación con la presencia de los virus en semen
}

Jorge Víctor Rosete Fernández ${ }^{\text {a }}$

Guadalupe A. Socci Escatell ${ }^{\text {b }}$

Abraham Fragoso Islas ${ }^{a}$

Juan Prisciliano Zárate Martínez ${ }^{\mathrm{c}}$

Sara Olazarán Jenkins ${ }^{\text {a }}$

Lorenzo Granados Zurita ${ }^{\mathrm{d}}$

Ángel Ríos Utrera ${ }^{c *}$

${ }^{a}$ Instituto Nacional de Investigaciones Forestales, Agrícolas y Pecuarias (INIFAP), Sitio Experimental Las Margaritas. Kilómetro 9.5 carretera Hueytamalco-Tenampulco, Hueytamalco, Puebla, México.

${ }^{\mathrm{b}}$ INIFAP, CENID Salud Animal e Inocuidad. Ciudad de México, México.

${ }^{\mathrm{c}}$ INIFAP, Campo Experimental La Posta. Veracruz, México.

${ }^{\mathrm{d}}$ INIFAP, Campo Experimental Huimanguillo. Tabasco, México.

*Autor de correspondencia: rios.angel@inifap.gob.mx

\section{Resumen:}

El objetivo fue estimar la frecuencia de anticuerpos séricos contra los virus de 
la rinotraqueitis infecciosa bovina (VRIB) y diarrea viral bovina (VDVB) en toros no vacunados, así como la relación entre la presencia de anticuerpos en suero y la presencia de dichos virus en semen. Los anticuerpos se detectaron mediante ELISA, mientras que la presencia de los virus en semen mediante PCR. Se realizaron análisis de regresión logística con PROC GENMOD de SAS. Los factores fueron: estado, hato anidado en estado, y genotipo del toro (excepto para la presencia de los virus en semen). El grado de asociación entre la presencia de anticuerpos séricos y la presencia de los virus en semen se midió mediante la correlación phi (r). Ninguno de los tres factores fue significativo $(P>0.05)$. Para el VRIB, la frecuencia de anticuerpos séricos por estado varió de 66 a $86 \%$, mientras que por hato varió de 28 a $90 \%$. Para el VDVB, la frecuencia de anticuerpos séricos por estado osciló de 58 a $76 \%$, mientras que por hato osciló de 43 a $86 \%$. La presencia del VRIB en semen, por estado, varió de 50 a $55 \%$, mientras que por hato varió de 33 a $80 \%$. No se encontró asociación $(P>0.05)$ entre la presencia de anticuerpos en suero y la presencia del VRIB $(\mathrm{r}=0.07)$ y VDVB en semen $(\mathrm{r}=0.16)$. La presencia de anticuerpos séricos sugiere la infección de los toros, pero la presencia de los virus en semen sugiere su transmisión por contacto sexual.

Palabras clave: Toros, Rinotraqueitis infecciosa bovina, Diarrea viral bovina, Anticuerpos, Antígenos, Semen, Trópico.

Recibido: 20/07/2020

Aceptado: 30/03/2021

\section{Introducción}

La diarrea viral bovina (DVB) es una enfermedad aguda y epizoótica ${ }^{(1)}$ debido a que ocasiona un amplio rango de lesiones y manifestaciones clínicas, así como considerables pérdidas en bovinos de carne y leche ${ }^{(2)}$, siendo los trastornos reproductivos los de mayor impacto económico ${ }^{(3)}$. Debido a su patogenia, la DVB se ha considerado la enfermedad viral más complicada en bovinos $^{(4)}$. 
Existen dos biotipos del virus de la DVB (VDVB): el citopático (CP) y el no citopático (NCP), según su comportamiento en cultivos celulares ${ }^{(2,4,5)}$. El biotipo común en la mayoría ( $95 \%$ ) de los aislamientos de campo es el NCP; el biotipo CP se genera por mutaciones o re-arreglos del genoma de la cepa original paterna NCP. Además, debido a sus características genéticasantigénicas se clasifican en dos genotipos, los cuales son el VDVB-1 y el VDVB-2, que son mayormente NCP. Estos biotipos y genotipos son cualidades independientes de los Pestivirus ${ }^{(6)}$.

Cada biotipo tiene un papel específico en una variedad de síndromes clínicos, tales como infecciones crónicas, agudas y congénitas. El VDVB-2 se ha asociado con brotes de infecciones agudas severas y el síndrome hemorrágico $^{(7)}$. La principal característica de este virus es su variabilidad genética y antigénica, debido a que los virus RNA se caracterizan por su plasticidad, la cual se debe a la falta de una exonucleasa eficiente para corregir las bases mal incorporadas, ocasionando una sustitución de base de alta frecuencia (un error por cada 10,000 nucleótidos polimerizados). El VDVB usa esta estrategia para sobrevivir, originando cepas mutantes que escapan a la respuesta inmunológica del hospedador.

El VDVB infecta principalmente bovinos, especie para la cual representa uno de los patógenos más importantes, pero también se puede encontrar en ovejas, cabras $^{(1)}$, porcinos, alpacas, llamas, camellos, búfalos de agua y rumiantes silvestres $^{(3)}$. Esta peculiaridad se debe tomar en cuenta a la hora de implementar un programa de control, ya que los Pestivirus cruzan la barrera de especie ${ }^{(3)}$. La gran diversidad de estudios disponibles indica que la DVB tiene una distribución mundial ${ }^{(6,8-11)}$, pues el virus es de alta morbilidad y baja mortalidad $^{(12)}$, de tal manera que un animal persistentemente infectado menor de cuatro meses de edad es capaz de infectar al $90 \%$ de sus compañeros de hato en condiciones estabuladas ${ }^{(13)}$.

Por su parte, la rinotraqueitis infecciosa bovina (RIB) es una enfermedad distribuida en diversas regiones de México, pues desde 1988 se han encontrado anticuerpos neutralizantes contra el virus de la RIB (VRIB) en bovinos del Estado de México, Puebla y Yucatán, a partir de bovinos con signos respiratorios que hacían sospechar de la presencia del virus ${ }^{(14)}$. En 
Tizimín, Yucatán, se observó una seroprevalencia de $5.33 \%^{(15)}$ y, posteriormente, en otro estudio en bovinos sin antecedentes de vacunación, se encontró una seroprevalencia de $54.4 \%{ }^{(16)}$, lo que demuestra que el VRIB está presente y latente en el trópico, pues su prevalencia ha ido en aumento, debido a que es altamente contagioso.

La RIB se manifiesta de diferentes maneras y se transmite por contacto directo con secreciones nasales, oculares y genitales, así como con semen fresco de toros infectados ${ }^{(17)}$. Esta enfermedad se ha investigado poco en toros, principalmente en hatos comerciales del trópico mexicano, pues, aunque se han reportado fallas reproductivas en vacas, no se ha actuado para identificar problemas sanitarios en toros. Por lo tanto, es importante estudiarla, pues en la mayoría de las vacas la enfermedad pasa desapercibida por no causar la muerte, teniendo como principal característica el aborto, afectando los parámetros reproductivos y productivos e incrementando notablemente las pérdidas económicas ${ }^{(18)}$, ya que existe menor producción de becerros para engorda y vaquillas de reemplazo.

Algunos estudios han demostrado la presencia del VRIB en semen congelado. En centros de inseminación artificial se han realizado aislamientos de este agente en toros clínicamente sanos ${ }^{(19)}$, pero poco se ha investigado sobre la presencia de este virus en semen de toros que se reproducen por medio de monta natural en hatos comerciales del trópico mexicano. En estudios previos, se reconoce que toros infectados son un factor de riesgo para la transmisión de la RIB, ya que su agente causal se transmite por vía venérea ${ }^{(20)}$, reactivándose la enfermedad en el hato y manteniéndolo infectado, lo cual explica los altos títulos de anticuerpos encontrados en algunas investigaciones en toros destinados para monta natural ${ }^{(21)}$. En hatos donde la reproducción ha sido a través de monta natural, se han encontrado prevalencias de $74.0^{(22)} \mathrm{y}$ $69.5 \%{ }^{(23)}$, poniendo de manifiesto la participación del macho en la transmisión de la enfermedad, a pesar de que las pruebas serológicas pudieran ser negativas ${ }^{(21)}$. En un estudio se observó que lafertilidad de toros no se afectó por la $\mathrm{RIB}^{(24)}$; por lo tanto, es un factor de riesgo que se debe considerar cuando se adquieren toros para monta sin control sanitario, lo que sin duda contribuye a empeorar la situación de la RIB en los hatos. 
Con base en lo anterior, el objetivo del presente trabajo fue estimar la frecuencia de anticuerpos séricos contra los virus de la DVB y RIB en toros no vacunados, así como la relación entre la presencia de anticuerpos en suero y la presencia de los virus en semen.

\section{Material y métodos}

El estudio se realizó en 14 hatos comerciales ubicados en el trópico y subtrópico de México en los estados de Puebla, Tabasco y Veracruz. Los hatos se ubican en el área de influencia de los campos experimentales del INIFAP: Las Margaritas, en Puebla, Huimanguillo, en Tabasco, y La Posta, en Veracruz.

Los hatos se seleccionaron con base en un muestreo no probabilístico por conveniencia, de acuerdo con el interés de los ganaderos de participar en el presente estudio. Por otro lado, el tamaño de muestra $(n=76)$ dependió de los toros existentes en cada hato participante. Los toros pertenecían a hatos oficialmente libres de Brucella abortus y Mycobacterium bovis, los cuales se dedicaban a la producción de carne y al doble propósito. El genotipo de los toros se clasificó en cebú (Bos indicus), europeo (Bos taurus) y cruzado (Bos taurus x Bos indicus).

Las muestras de sangre se obtuvieron de la vena coccígea y se conservaron entre 4 y $6{ }^{\circ} \mathrm{C}$ en una hielera hasta llegar al laboratorio del campo experimental correspondiente, donde se centrifugaron a 4,000 rpm durante $10 \mathrm{~min}$, para obtener $3 \mathrm{ml}$ de suero/toro. Las muestras de suero se conservaron en viales de polietileno a $-20{ }^{\circ} \mathrm{C}$ hasta el momento de su análisis. El diagnóstico serológico para la detección de anticuerpos contra los virus de la RIB y de la DVB se realizó con los kits CIVTEST BOVIS IBR y CIVTEST BOVIS BVD/BD P80 (Laboratorios Hipra, S.A., México), basados en la prueba de ELISA, cuya sensibilidad y especificidad es 96.3 y $99.5 \%$, respectivamente. En ambos diagnósticos serológicos, la lectura se realizó a una densidad óptica de 450 nanómetros, en un espectrofotómetro ELx800, marca BioTek (BioTek Instruments, Inc., EUA). 
Las muestras de semen ( $3 \mathrm{ml} /$ toro) se obtuvieron por medio de electroeyaculación y se contuvieron en tubos de polietileno; posteriormente, se mantuvieron entre 4 y $6{ }^{\circ} \mathrm{C}$ en una hielera. Al llegar al laboratorio, las muestras se conservaron en congelación a $-20^{\circ} \mathrm{C}$ hasta el momento de su análisis. Estas muestras fueron analizadas por PCR para detectar antígenos de los virus mencionados. De cada muestra de semen ya homogenizada, se tomaron 200 $\mu 1$ para la extracción de ácidos nucleicos mediante el paquete comercial High Pure PCR Template Preparation Kit (Laboratorios Roche), bajo el protocolo descrito por el fabricante para muestras de sangre completa, con la modificación de que, en el último paso, los ácidos nucleicos se eluyeron en $50 \mu \mathrm{l}$ de agua inyectable bidestilada. La amplificación del ADN para la detección del virus de la RIB se realizó con la utilización de un par de iniciadores que amplifican $468 \mathrm{pb}$ del gen de la glicoproteína $\mathrm{gI}^{(25)}$. La mezcla de reacción se elaboró en un volumen final de $25 \mu 1$ con las siguientes concentraciones: $1 \mathrm{X}$ de Buffer 10X, $1.5 \mathrm{mM}$ de $\mathrm{MgCl}_{2}, 0.4 \mathrm{mM}$ de dNTP's, 20 pmol de cada iniciador, $1.25 \mathrm{U}$ de Taq polimerasa y $1.5 \mathrm{mcg}$ de BSA. El programa de amplificación constó de 1 ciclo a $95^{\circ} \mathrm{C}$ durante $1 \mathrm{~min} ; 35$ ciclos a $95{ }^{\circ} \mathrm{C}$ durante $1 \mathrm{~min}, 62{ }^{\circ} \mathrm{C} 1 \mathrm{~min}$ y $72{ }^{\circ} \mathrm{C} 1 \mathrm{~min}$; y un ciclo final a $72{ }^{\circ} \mathrm{C}$ durante $7 \mathrm{~min}$. La electroforesis de los productos de amplificación se llevó a cabo en geles de agarosa al 1.5\%, teñidos con el reactivo GelRed (Biotium). La visualización de los productos de amplificación se realizó bajo luz UV en un fotodocumentador.

Para la detección del virus de la DVB se realizó la síntesis de cDNA y su amplificación en un solo paso. Se utilizaron un par de iniciadores que amplifican un fragmento de 191 pb de la región 5' UTR del genoma viral ${ }^{(26)}$. La reacción se llevó a cabo en un volumen final de $25 \mu$ l bajo las siguientes condiciones: $1 \mathrm{X}$ de Buffer 10X, $1.5 \mathrm{mM}$ de $\mathrm{MgCl}_{2}, 0.4 \mathrm{mM}$ de dNTP's, 20 pmol de cada iniciador, $1.25 \mathrm{U}$ de Taq polimerasa, $6 \mathrm{U}$ de Transcriptasa reversa y $1.5 \mathrm{mcg}$ de BSA. El programa de amplificación consistió en 1 ciclo a $48{ }^{\circ} \mathrm{C}$ durante $30 \mathrm{~min}$, seguido de 1 ciclo a $95{ }^{\circ} \mathrm{C}$ durante $10 \mathrm{~min} ; 35$ ciclos a $94{ }^{\circ} \mathrm{C}$ durante $1 \mathrm{~min}, 58{ }^{\circ} \mathrm{C}$ durante $1 \mathrm{~min}, 72^{\circ} \mathrm{C}$ durante $1 \mathrm{~min}$; y un ciclo de extensión final de $72{ }^{\circ} \mathrm{C}$ durante $7 \mathrm{~min}$. La electroforesis y la visualización se realizaron de la misma forma que para el virus de la RIB. 
Las frecuencias de anticuerpos en suero, así como las frecuencias de antígenos en semen, se trataron como características binarias, por lo que se registraron como 1 cuando un toro resultó positivo a la prueba de ELISA o PCR, respectivamente; en caso contrario, como 0 . El modelo estadístico (modelo de regresión logística binomial) para analizar las frecuencias de anticuerpos incluyó los factores estado de la República Mexicana, hato anidado en estado y genotipo del toro; para analizar las frecuencias de antígenos en semen, el modelo estadístico solo incluyó estado de la República Mexicana y hato anidado en estado de la República Mexicana. Se realizaron análisis de regresión logística por característica, con el procedimiento GENMOD del paquete SAS, utilizando una función liga logit para la distribución binomial. El criterio de convergencia aplicado en cada análisis estadístico fue $10^{-8}$.

El grado de asociación entre la presencia de anticuerpos en suero y de antígenos en semen de los virus de la DVB y RIB, como indicador de la eliminación de los virus a través del semen, se determinó con el coeficiente phi, también llamado coeficiente de correlación de Mathews, el cual se calcula para tablas de contingencia $2 \times 2$, toros positivos (1) o negativos (0) para la presencia de anticuerpos en suero, y toros positivos (1) o negativos (0) para la presencia de antígenos en semen. Los coeficientes de correlación, así como la significancia estadística para determinar si eran diferentes de cero, se estimaron con el procedimiento CORR del paquete SAS.

\section{Resultados y discusión}

Ninguno de los tres factores de ajuste afectó $(P>0.05)$ la frecuencia de anticuerpos séricos contra el VDVB. La frecuencia de antígenos en semen del VDVB no fue estimable, ya que una gran proporción de los toros fueron negativos a la prueba de PCR (97.4\%), resultando en la ausencia de variación en algunos de los factores de ajuste incluidos en el modelo estadístico. Las frecuencias de anticuerpos séricos contra el VDVB y sus intervalos de confianza al 95\%, por estado y genotipo se presentan en los Cuadros 1 y 2 , respectivamente; sin embargo, las frecuencias por hato no se presentan. $\mathrm{La}$ frecuencia de anticuerpos séricos contra el VDVB varió de 58 a $76 \%$ por estado, de 43 a $86 \%$ por hato, y de 54 a $79 \%$ por genotipo. No se encontró asociación $(P>0.05)$ entre la presencia de anticuerpos en suero y la presencia 
del VDVB en semen $(r=0.16)$.

Cuadro 1: Frecuencias ( \pm errores estándar) de anticuerpos séricos contra el virus de la diarrea viral bovina e intervalos de confianza al 95\%, por estado

\begin{tabular}{cccc}
\hline Estado & No. de toros & Frecuencia, \% & Intervalo \\
\hline Puebla & 28 & $58 \pm 11$ & $36-77$ \\
Tabasco & 26 & $59 \pm 11$ & $38-78$ \\
Veracruz & 22 & $76 \pm 11$ & $49-92$ \\
\hline \multicolumn{4}{r}{$(P>0.05)}$.
\end{tabular}

Cuadro 2: Frecuencias ( \pm errores estándar) de anticuerpos séricos contra el virus de la diarrea viral bovina e intervalos de confianza al 95\%, por genotipo

\begin{tabular}{cccc}
\hline Genotipo & No. de toros & Frecuencia, \% & Intervalo \\
\hline Cebú & 29 & $54 \pm 13$ & $29-77$ \\
Cruza & 33 & $60 \pm 10$ & $40-77$ \\
Europeo & 14 & $79 \pm 14$ & $43-95$ \\
\hline \multicolumn{4}{c}{$(P>0.05)}$.
\end{tabular}

La frecuencia de anticuerpos séricos contra el VDVB estimada en el presente estudio es relativamente alta y, en consecuencia, de consideración. Por lo tanto, sabiendo de antemano que en los hatos evaluados la reproducción se realizó mediante monta natural, los toros representan un factor de riesgo en la transmisión de la DVB. Por otro lado, aunque la frecuencia de antígenos en semen del VDVB no se pudo estimar mediante un modelo estadístico, ésta se considera baja, ya que una gran proporción de toros resultó negativa a la prueba de PCR (97.4\%), lo que sugiere que no todos los sementales estaban eliminando el virus al momento de tomar la muestra de semen, o bien, existe la posibilidad que solo los toros persistentemente infectados (PI) eliminaron el virus, ya que se ha demostrado que el virus se replica en la próstata y vesículas seminales en toros PI y no se elimina constantemente ${ }^{(27,28,29)}$. En otro estudio en toros de Perú, también se observó una frecuencia de anticuerpos séricos relativamente alta $(51.3 \%)$, argumentándose una amplia difusión y actividad viral entre animales y enfatizándose el riesgo de transmisión a través del semen ${ }^{(29)}$, por lo que es importante la vacunación en hembras, para prevenir problemas reproductivos por el riesgo de infección ${ }^{(27)}$. 
La frecuencia de anticuerpos séricos contra el VDVB hallada en este estudio sugiere que los hatos a los que pertenecen los toros están infectados y expuestos permanentemente a la reinfección, y en cuanto a la frecuencia del VDVB en semen, se esperaba que ésta fuera mucho mayor, y que mostrara una alta correlación con la presencia de anticuerpos en suero, pero esto no sucedió debido, probablemente, a que el VDVB no se elimina constantemente a través del semen ${ }^{(29)}$; sin embargo, aún la presencia mínima del VDVB en semen representa un factor de riesgo en el momento de la monta natural, como lo han argumentado otros autores ${ }^{(28,30)}$, y si se trata de semen congelado, éste debe ser inocuo, pues al infectar a las vacas inseminadas causa problemas de fertilidad $^{(31-33)}$, por el riesgo de la eliminación del virus, aunque no permanentemente en el eyaculado de los toros $\mathrm{PI}^{(28,29,34)}$. Esto lo demuestra un estudio en toros de dos años de edad, sin antecedentes de DVB e inoculados vía nasal con el $\operatorname{VDVB}^{(35)}$, que eliminaron el virus en semen durante un periodo de hasta siete meses, para después desaparecer, lo que puede explicar por qué muy pocos toros eliminaron el virus en semen en el presente estudio, pues no se elimina constantemente ${ }^{(29,34,35)}$. Aun así, la detección del VDVB en suero o semen es importante en sementales para monta natural o congelación de semen, pues al impedir la utilización de animales positivos, se minimiza el riesgo de transmisión a las hembras ${ }^{(28,30)}$.

Debido a que la DVB persiste en animales infectados, se facilita su transmisión a animales sanos ${ }^{(3,7,36,37)}$, entonces, la vacunación es la herramienta de control apropiada, pues la eliminación de animales PI es complicada y requiere de mucho tiempo. Por lo tanto, los hatos evaluados en este estudio se deberían vacunar ${ }^{(27)}$ para prevenir problemas reproductivos ${ }^{(29)}$.

Para la frecuencia de anticuerpos séricos contra el VRIB, el estado, hato anidado en estado y genotipo del toro tampoco fueron factores de ajuste importantes $(P>0.05)$. En los Cuadros 3 y 4 se muestran las frecuencias de anticuerpos séricos contra el VRIB y sus intervalos de confianza al 95\%, por estado y genotipo del toro, respectivamente; sin embargo, las frecuencias por hato no se presentan. La frecuencia de anticuerpos séricos contra este virus varió de 66 a $83 \%$ por estado, de 28 a $90 \%$ por hato, y de 54 a $84 \%$ por genotipo. 
Cuadro 3: Frecuencias ( \pm errores estándar) de anticuerpos séricos contra el virus de la rinotraqueitis infecciosa bovina e intervalos de confianza al 95\%, por Estado

\begin{tabular}{cccc}
\hline Estado & No. de toros & Frecuencia, \% & Intervalo \\
\hline Puebla & 34 & $83 \pm 7$ & $63-93$ \\
Tabasco & 11 & $66 \pm 18$ & $29-90$ \\
Veracruz & 29 & $70 \pm 10$ & $47-86$ \\
\hline \multicolumn{4}{c}{$(P>0.05)}$.
\end{tabular}

Cuadro 4: Frecuencias ( \pm errores estándar) de anticuerpos séricos contra el virus de la rinotraqueitis infecciosa bovina e intervalos de confianza al 95\%, por genotipo

\begin{tabular}{cccc}
\hline Genotipo & No. de toros & Frecuencia, \% & Intervalo \\
\hline Cebú & 33 & $79 \pm 10$ & $52-92$ \\
Cruza & 29 & $54 \pm 13$ & $30-76$ \\
Europeo & 12 & $84 \pm 12$ & $46-97$ \\
\hline \multicolumn{4}{c}{$(P>0.05)}$.
\end{tabular}

La presencia del VRIB en semen tampoco fue afectada por los efectos de estado y hato; la frecuencia correspondiente varió de 50 a $55 \%$ por estado (Cuadro 5) y de 33 a $80 \%$ por hato (estas frecuencias no se presentan). La presencia de anticuerpos en suero y la presencia del VRIB en semen tampoco estuvieron correlacionadas $(\mathrm{r}=0.07 ; P>0.05)$.

Cuadro 5: Frecuencias ( \pm errores estándar) para el virus de la rinotraqueitis infecciosa bovina en semen e intervalos de confianza al 95\%, por Estado

\begin{tabular}{cccc}
\hline Estado & No. de toros & Frecuencia, \% & Intervalo \\
\hline Puebla & 21 & $54.9 \pm 12.5$ & $31-77$ \\
Tabasco & 12 & $50.0 \pm 15.3$ & $23-77$ \\
Veracruz & 23 & $52.3 \pm 10.4$ & $33-71$ \\
\hline
\end{tabular}

$(P>0.05)$.

Los resultados de este estudio muestran una frecuencia de anticuerpos séricos contra el VRIB relativamente alta. Una frecuencia similar $(69.5 \%)$ se encontró en toros cruzados de doble propósito de hatos del municipio de 
Tonalá, Chiapas ${ }^{(23)}$, así como en toros cruzados para producción de carne y doble propósito de hatos de la Sierra Oriente de Puebla $(76.0 \%)^{(24)}$ y de toros para producción de carne en Yucatán $(54.4 \%)^{(16)}$. Por otro lado, en toros para producción de carne de hatos del Istmo y de la Costa de Oaxaca ${ }^{(38)}$ se observaron frecuencias menores (31.6 y $27.9 \%$, respectivamente). En estudios realizados en toros colombianos se observaron frecuencias relativamente altas, $85.5 \%$ en Antioquia ${ }^{(20)}, 67.6 \%$ en Urabá y $75.0 \%$ en el Valle del Cauca ${ }^{(39)}$.

En cuanto a la presencia del VRIB en semen, se ha documentado la identificación del virus en toros para monta natural, así como en sementales de centros de inseminación artificial ${ }^{(40)}$, en los que se han podido aislar ambos virus a partir de pajuelas de semen congelado de varias casas comerciales ${ }^{(41)}$, evidenciando que la inseminación artificial también es un factor de riesgo importante en la propagación de la RIB, ya que es un patógeno frecuentemente presente en semen, asociado con baja calidad del mismo. El virus se encuentra más en el plasma seminal que en la fracción celular, de tal manera que su transmisión ha mostrado pérdida de la fertilidad en vacas ${ }^{(31)}$.

En este estudio no se encontró asociación entre la relativamente alta frecuencia de anticuerpos y la presencia del VRIB en semen, en los que hubo solo un $53 \%$ de toros eliminadores del virus, en contraste con un estudio previo $^{(40)}$ en el que del total de toros seropositivos a anticuerpos contra el virus, el $100 \%$ lo eliminaron en el semen. Lo anterior se puede deber a factores que inducen la excreción o reactivación del virus, como el estrés calórico, el estrés por manejo, los tratamientos con cortico-esteroides, que causan inmunosupresión, lo que permite que el virus se replique en las células epiteliales y otros tejidos (ocular, por ejemplo), sin que llegue a los órganos reproductores; o bien, que suceda lo contrario, que el sistema inmune esté funcionando perfectamente, evitando la replicación del virus y, por lo tanto, el virus no se encuentra en semen en el momento de la eyaculación ${ }^{(42-44)}$. Sin embargo, la detección de anticuerpos contra el VRIB y de antígenos en semen, juntas o separadas, son efectivas para detectar la enfermedad en los toros ${ }^{(45)}$ $\mathrm{y}$, por ende, en el hato. Finalmente, debido a las altas frecuencias de anticuerpos en suero y del VRIB en semen en este estudio y considerando que la enfermedad también se transmite por contacto sexual, es importante señalar 
que urge una campaña de control para la RIB en México, como se ha hecho en Brasil ${ }^{(46)}$.

\section{Conclusiones e implicaciones}

No se encontró asociación entre la presencia de anticuerpos en suero y la presencia de los virus en semen; tampoco se encontraron diferencias entre estados en la frecuencia de anticuerpos séricos contra los virus de la RIB y DVB ni en la frecuencia de antígenos en semen del VRIB. Sin embargo, dichas frecuencias fueron de magnitud considerable, por lo que se debería implementar un programa de control mediante la vacunación. Si un toro elimina estos virus a través del semen se puede considerar persistentemente infectado, lo que también debe tomarse en cuenta antes de comprar sementales, los cuales deberían estar libres de DVB y RIB, comprobado con pruebas de laboratorio.

\section{Literatura citada:}

1. Obando RCA, Rodríguez JM. Diarrea viral bovina. En: González-Stagnaro C, Soto BE editores. Manual de ganadería doble propósito. $1^{\mathrm{a}}$ ed. Maracaibo, Venezuela: Astro Data, S. A.; 2005:317-322.

2. Rondón I. Diarrea viral bovina: Patogénesis e inmunopatología. Rev MVZ Córdoba 2006;11(1):694-704.

3. Lértora WJ. Diarrea viral bovina: Actualización. Rev Vet FCV UNNE 2003;14(1):1-11.

4. Ramírez RR, Chavarría MB, López MA, Rodríguez TLE, Nevárez GAM. Presencia del virus de la diarrea viral bovina y su asociación con otros cuadros patológicos en ganado en corral de engorda. Vet Méx 2012;43(3):225-234.

5. Vargas DS, Jaime J, Vera JV. Perspectivas para el control del virus de la diarrea viral bovina (BVDV). Rev Colomb Cienc Pecu 2009;22:677-688. 
6. Carter GR, Wise DJ, Flores EF. Flaviviridae. En: Carter GR, Wise DJ, Flores EF eds. Virología veterinaria. International Veterinary Information Service, Ithaca NY. 2005:251-262.

7. OIE. Office International des Epizooties. Diarrea Viral Bovina. Manual de la OIE Sobre Animales Terrestres. 2008:1-15.

8. Bedekovic T, Lemo N, Barbic L, Cvetnic Z, Lojkic I, Benic M, et al. Influence of category, herd size, grazing and management on epidemiology of bovine viral diarrhoea in dairy herds. Acta Vet Brno 2013;82:125-130.

9. Chowdhury MMR, Afrin F, Saha SS, Jhontu S, Asgar MA. Prevalence and haematological parameters for bovine viral diarrhoea (BVD) in South Bengal areas in Bangladesh. The Bangladesh Vet 2015;32(2):48-54.

10. Handel IG, Willoughby K, Land F, Koterwas B, Morgan KL, Tanya VN, et al. Seroepidemiology of bovine viral diarrhoea virus (BVDV) in the Adamawa region of Cameroon and use of the SPOT test to identify herds with PI calves. Plos One 2011;6(7):e21620.

11. Luzzago C, Lauzi S, Ebranati E, Giammarioli M, Moreno A, Cannella V, et al. Extended genetic diversity of bovine viral diarrhea virus and frequency of genotypes and subtypes in cattle in Italy between 1995 and 2013. BioMed Res Int 2014:1-8.

12. Gasque GR. Diarrea Viral Bovina. $1^{\text {a }}$ Ed. México, D.F.: UNAM; 2008.

13. Houe H. Survivorship of animals persistently infected with bovine viral diarrhoea virus (BVDV). Pre Vet Med 1993;15:275-283.

14. Correa, G. Complejo reproductivo bovino. En: Correa, G. Enfermedades virales de los animales domésticos poligástricos. $5^{\text {a }}$ ed. Paradigmas. México, D.F. 1988:45-90.

15. Calderón VG, Alvarado IA, Vilchis MC, Aguilar SA, Batalla CD. Detección de seropositividad al virus de rinotraqueitis infecciosa bovina (IBR) en ganado del municipio de Tizimín, Yucatán, México. Téc Pecu Méx 1997;35(3):161-164. 
16. Solis-Calderon JJ, Segura VM, Segura JC, Alvarado IA. Seroprevalence of and risk factors for infection bovine rhinotracheitis in beef cattle herds of Yucatan, Mexico. Prev Vet Med 2003;57(4):199-208.

17. Nuotio L, Neuvonen E, Hyytiäinen M. Epidemiology and eradication of infectious bovine rhinotracheitis/infectious pustular vulvovaginitis (IBR/IPV) virus in Finland. Acta Vet Scand 2007;49(3):1-6.

18. Bracho CA, Jaramillo ACJ, Martínez, MJJ, Montaño HJA, Olguín BA. Comparación de tres pruebas diagnósticas para el aborto por rinotraqueitis infecciosa bovina en hatos lecheros. Vet Méx 2006;37:151163.

19. Martínez CPJ, Riveira SIM. Antecedentes, generalidades y actualización en aspectos de patogénesis, diagnóstico y control de la diarrea viral bovina (DVB) y rinotraqueitis infecciosa bovina [tesis licenciatura]. Bogotá D.C., Colombia: Pontificia Universidad Javeriana; 2008.

20. Ruiz J, Jaime J, Vera VJ. Prevalencia serológica y aislamiento del Herpesvirus Bovino-1 (BHV-1) en hatos ganaderos de Antioquia y del Valle del Cauca. Rev Colomb Cienc Pecu 2010;23:299-307.

21. Schroeder WH. IBR-IPV y Reproducción. En: Schroeder WH editor. Fisiopatología reproductiva de la vaca. $1^{a}$ ed. Bogotá, Colombia: Celsus; 1999:825-833.

22. Romero-Salas D. Enfermedades que causan abortos en la ganadería bovina. $1^{a}$ ed. Veracruz, Veracruz: Universidad Veracruzana; 2012.

23. De los Santos MC, Orantes MA, Sánchez B, Manzur A, Cruz JL, Ruiz JL, et al. Determinación de anticuerpos de IBR mediante la técnica de ELISA en la zona Paredón- Boca del Cielo, Tonalá, Chiapas. Quehacer Cient Chis 2013;8(1):31-34.

24. Soto JR. Prevalencia de anticuerpos a IBR, BVD, Leptospirosis y Neosporosis y su relación con la fertilidad en sementales bovinos productores de carne del subtrópico húmedo de puebla [tesis licenciatura]. Puebla, México: Benemérita Universidad Autónoma de Puebla; 2014. 
25. Deka D, Ramneek, Maiti NK, Oberoi MS. Detection of bovine herpesvirus-1 infection in breeding bull semen by virus isolation and polymerase chain reaction. Rev Sci Tech Off Int Epiz 2005;24(3):10851094.

26. Sandvik T, Paton DJ, Lowings PJ. Detection and identification of ruminant and porcine pestiviruses by nested amplification of 5 , untranslated cDNA regions. J Virol Methods 1997;64:43-56.

27. González-Altamiranda EA, Kaiser GG, Weber N, Leunda MR, Pecora A, Malacan DA, et al. Clinical and reproductive consequences of using BVDV-contaminated semen in artificial insemination in a beef herd in Argentina. Anim Reprod Sci 2012;133(3-4):146-152.

28. Givens MD, Waldrop JG. Bovine viral diarrhea virus in embryo and semen production systems. Vet Clin Food Anim 2004;20(1):21-38.

29. Cárdenas AC, Rivera GH, Araínga RM, Ramírez VM, De Paz MJ. Prevalencia del virus de la diarrea viral bovina y de animales portadores del virus en bovinos en la provincia de Espinar, Cusco. Rev Inv Vet Perú 2011;22(3):261-267.

30. Mishra N, Kalaiyarasu S, Mallinath KC, Rajukumar K, Khetan RK, Gautam S, et al. Identification of bovine viral diarrhoea virus type 2 in cattle bull semen from southern India and its genetic characterization. Current Sci 2018;114(3):666-670.

31. Dejucq N, Jégou B. Viruses in the mammalian male genital tract and their effect on reproductive system. Microbiol Mol Biol R 2001;65(2):208231.

32. Kirkland PD, McGowan MR, Mackintosh SG, Moyle A. Insemination of cattle with semen from a bull transiently infected with pestivirus. Vet Rec 1997;140:124-127.

33. Meyling A, Jensen AM. Transmission of bovine virus diarrhoea virus (BVDV) by artificial insemination (AI) with semen from a persistentlyinfected bull. Vet Microbiol 1998;17:97-105. 
34. Niskanen R, Alenius S, Belák K, Baule C, Belák S, Voges H, Gustafsson $H$. Insemination of susceptible heifers with semen from a non-viraemic bull with persistent bovine virus diarrhoea virus infection localized in the testes. Reprod Dom Anim 2002;37:171-175.

35. Givens MD, Heath AM, Carson RL, Brock KV, Edens MSD, Wenzel $\mathrm{JGW}$, et al. Analytical sensitivity of assays used for detection of bovine viral diarrhea virus in semen samples from the Southeastern United States. Vet Microbiol 2003;96(2):145-155.

36. Edmondson MA, Givens MD, Walz PH, Gard JA, Stringfellow DA, Carson RL. Comparison of tests for detection of bovine viral diarrhea virus in diagnostic samples. J Vet Diagn Invest 2007;19:376-381.

37. Grooms DL. Reproductive consequences of infection with bovine viral diarrhea virus. Vet Clin North Am Food Anim Pract 2004;20:5-19.

38. Hernández BEG, Gutiérrez HJL, Herrera LE, Palomares REG, DíazAE. Frecuencia de diarrea viral bovina, rinotraqueitis infecciosa bovina, leptospirosis y brucelosis, en las 2 regiones ganaderas más importantes de Oaxaca. En: González IDR, Posadas ME editores. XXXIX Congreso Nacional de Buiatría. 2015:87-92.

39. Peña MA, Góngora A, Jiménez C. Infectious agents affecting fertility of bulls, and transmission risk through semen. Retrospective analysis of their sanitary status in Colombia. Rev Colomb Cienc Pecu 2011;24:634646.

40. Oliveira MT, Campos FS, Dias MM, Velho FA, Freneau GE, Brito WMED, et al. Detection of bovine herpesvirus 1 and 5 in semen from Brazilian bulls. Theriogenology 2011;75:1139-1145.

41. Morán PE, Favier PA, Lomónaco M, Catena MC, Chiapparrone ML, Odeón AC, et al. Search for the genome of bovine herpesvirus types 1, 4 and 5 in bovine semen. Open Vet J 2013;3(2):126-130.

42. Gregersen JP, Wagner K. Persistent infection of the genital tract and excretion of the vaccine strain after live virus inmunization with bovine herpesvirus 1 (IBR/IPV virus). Zentralbl Veterinaermed B 1985;32:1-10. 
43. Alonzo P, Puentes R, Benavides U, Esteves PA, Silva AD, Roehe PM, et al. Infección natural de un toro con dos subtipos diferentes de herpesvirus bovino tipo 1. Veterinaria (Montevideo) 2011;48(184):5-10.

44. Duque D, Estévez JNR, Abreu AM, Moncada M, Durango J, Molina D. Aspectos sobre rinotraqueitis infecciosa bovina. J Agric Anim Sci 2014;3(1):58-71.

45. Jain L, Kanani AN, Kumar V, Joshi CG, Purohit JH. Detection of bovine herpesvirus 1 infection in breeding bulls by ELISA and PCR assay. Indian J Vet Res 2009;18(1):1-4.

46. Sá Filho MFL, Vieira LCM, Martins CA, Rodríguez PS. New approaches in superovulation programs and embryo transfer in Brazil. Curso Internacional de Biotecnologías Reproductivas en Ganadería Tropical. 2013:1-9. 